\title{
Best transcatheter approach for a failed mitral valve ring
}

\author{
J. James Edelman ${ }^{1}$, John J. Squiers ${ }^{2}$, Michael J. Mack $^{2,3}$, Vinod H. Thourani ${ }^{4}$ \\ ${ }^{1}$ Fiona Stanley Hospital, University of Western Australia, Perth, Australia; ${ }^{2}$ Baylor Scott \& White Research Institute, Plano, Texas, USA; \\ ${ }^{3}$ Department of Cardiothoracic Surgery, Baylor Scott \& White, The Heart Hospital, Plano, Texas, USA; ${ }^{4}$ Department of Cardiovascular Surgery, \\ Marcus Valve Center, Piedmont Heart Institute, Atlanta, Georgia, USA \\ Correspondence to: Vinod H. Thourani, MD. Department of Cardiovascular Surgery, Piedmont Heart Institute, 95 Collier Road, Suite 5015, Atlanta, \\ GA 30309, USA. Email: vinod.thourani@piedmont.org.
}

Submitted Jun 13, 2021. Accepted for publication Jul 14, 2021.

doi: 10.21037/acs-2021-tviv-22

View this article at: https://dx.doi.org/10.21037/acs-2021-tviv-22

The use of an annuloplasty band or ring to restore the mitral valve (MV) annulus and geometry is a key principle of MV repair for degenerative or functional pathology. The need for re-operation after MV repair is just over $5 \%$ at ten years for degenerative disease from a number of large case series reported from expert MV centers (1). This is much higher in those undergoing MV repair for ischemic mitral regurgitation (MR) - at two years after surgery for severe ischemic $\mathrm{MR}$, there was recurrent moderate or severe MR in $58.8 \%$ of patients with MV repair, compared with $3.8 \%$ in those with MV replacement (2). Unfortunately, the true rate of MV repair failure is difficult to estimate due to the relatively short period of follow-up in large national databases. Re-operative MV surgery (including previous MV replacement) consists approximately $10 \%$ of all MV surgery and is associated with high mortality $-11 \%$ in a large regional US database (3). However, the results of re-operative MV surgery after previous MV repair may be lower at $1-9 \%$, as reported in a number of smaller case series $(4,5)$.

Transcatheter valve technology has increased the options for patients requiring re-operative mitral valvular repair surgery. Transcatheter MV replacement within a degenerated MV bioprosthesis (MViV) is associated with good results and is becoming a common alternative to reoperative surgery. However, transcatheter MV replacement in a previous annuloplasty $(\mathrm{MViR})$ is more challenging. The most common complication remains the risk of left ventricular outflow tract (LVOT) obstruction as the anterior MV leaflet is displaced by the prosthesis into the outflow tract. The commonly used balloon-expandable valves are effective in most cases, but may be difficult to anchor in all but semi-rigid complete annuloplasty rings, and are not big enough to be implanted in ring sizes greater than $34 \mathrm{~mm}$. Dedicated transcatheter MV prostheses, such as the Tendyne (Abbott, Abbott Park, IL, USA), have improved anchoring and sealing in replacement of the native MV. There are reports of this device being used in a failed annuloplasty ring (6) with success, but have not been approved for use in the United States (U.S.) or worldwide.

The overall number of MViR cases included in registries remains small. The VIVID Registry includes 222 patients who have had MViR (51\% transapical); whilst procedural mortality was low $(0.5 \%), 30$-day mortality was $8.6 \%$ and procedural success $63 \%$ (7). In the TMVR Multicenter Registry, 141 patients undergoing MViR (65\% transapical) were included and reported to have $9.9 \%$ 30-day mortality and $57 \%$ procedural success (8). Although there remains trans-apical (TA) or trans-septal (TS) approaches for delivery of the transcatheter MV replacement, the clear preference of Heart Teams is to use the TS approach. A recent analysis from the national U.S. Society of Thoracic Surgeons (STS)/ American College of Cardiology (ACC) Transcatheter Valve Therapies (TVT) database showed an increase in TS approach from $<16 \%$ in $2006-2013$ to $>80 \%$ in $2018-2020$ (9). The most commonly used valve for MViR procedures remains the balloon-expandable SAPIEN valve (Edwards Lifesciences, Irvine, CA, USA) which can be delivered across the interatrial septum using the Commander delivery system (Edwards Lifesciences, Irvine, CA, USA) from the femoral vein. The location of the transeptal puncture is important and should be inferior and posterior to allow enough room for the delivery system to perform the approximately 90 -degree bend required to traverse the prior $M V$ prosthesis. It is possible that paravalvular regurgitation between the prior $\mathrm{MV}$ prosthesis and SAPIEN valve can occur and the operators should be skilled to close these gaps using transcatheter 
closure devices.

A major limitation of the MViR procedure is the risk of LVOT obstruction by displacement of the anterior leaflet by the prosthesis towards the interventricular septum. LVOT is associated with a high mortality and may occur when the neoLVOT is $<250 \mathrm{~mm}^{2}$. In some instances, the Laceration of the Anterior Mitral leaflet to Prevent Outflow ObstructioN (LAMPOON) procedure, which uses catheter electrosurgery to lacerate the anterior leaflet in the septo-lateral (or anteriorposterior) plane may prevent LVOT obstruction (10). In brief, two retrograde sheaths are placed from the femoral arteries, one in the left atrium and the other in the LVOT. An electrified wire is passed through the base of the anterior MV leaflet and captured by a snare placed through the left atrial catheter. Under tension and electrified through a small area on the wire stripped of its insulation, the anterior MV leaflet is lacerated from its base along the length of the $\mathrm{A} 2$ segment. This laceration allows lateral and medial displacement of each "half" of the anterior leaflet, preventing obstruction of the LVOT.

Although the outcomes of re-operative surgery for failed surgical MV repair are better than those for a failed MV replacement, a reliable less invasive transcatheter option that delivers equivalent or superior outcomes to re-operative surgery would be ideal. The adjuncts to MViR to prevent LVOT obstruction, such as LAMPOON, are effective, and large reference centers with transcatheter programs should become competent in their execution.

\section{Acknowledgments}

Funding: None.

\section{Footnote}

Conflicts of Interest: Dr. MJM is a trial investigator for Edwards Lifesciences, Medtronic and Abbott; Dr. Thourani is an advisor for Edwards Lifesciences. The other authors have no conflicts of interest to declare.

Open Access Statement: This is an Open Access article distributed in accordance with the Creative Commons Attribution-NonCommercial-NoDerivs 4.0 International License (CC BY-NC-ND 4.0), which permits the noncommercial replication and distribution of the article with the strict proviso that no changes or edits are made and the original work is properly cited (including links to both the formal publication through the relevant DOI and the license). See: https://creativecommons.org/licenses/by-nc-nd/4.0/.

\section{References}

1. Gillinov AM, Blackstone EH, Nowicki ER, et al. Valve repair versus valve replacement for degenerative mitral valve disease. J Thorac Cardiovasc Surg 2008;135:885-93, 893. e1-2.

2. Goldstein D, Moskowitz AJ, Gelijns AC, et al. Two-Year Outcomes of Surgical Treatment of Severe Ischemic Mitral Regurgitation. N Engl J Med 2016;374:344-53.

3. Mehaffey HJ, Hawkins RB, Schubert S, et al. Contemporary outcomes in reoperative mitral valve surgery. Heart 2018;104:652-6.

4. Aphram G, De Kerchove L, Mastrobuoni S, et al. Rerepair of the failed mitral valve: insights into aetiology and surgical management. Eur J Cardiothorac Surg 2018;54:774-80.

5. Nishida H, Fukui T, Kasegawa H, et al. Causes of repair failure for degenerative mitral valve disease and reoperation outcomes. Eur J Cardiothorac Surg 2018;53:1244-50.

6. Pozzoli A, Gavazzoni M, Maisano F, et al. Transcatheter mitral valve replacement after transcatheter direct annuloplasty with Cardioband. Eur Heart J 2020;41:3765.

7. Simonato M, Whisenant B, Ribeiro HB, et al. Transcatheter Mitral Valve Replacement After Surgical Repair or Replacement: Comprehensive Midterm Evaluation of Valve-in-Valve and Valve-in-Ring Implantation From the VIVID Registry. Circulation 2021;143:104-16.

8. Yoon SH, Whisenant BK, Bleiziffer S, et al. Outcomes of transcatheter mitral valve replacement for degenerated bioprostheses, failed annuloplasty rings, and mitral annular calcification. Eur Heart J 2019;40:441-51.

9. Mack MJ, Carroll JD, Thourani V, et al. Transcatheter mitral valve therapy in the US: A 2020 report from the STS-ACC TVT Registry. J Am Coll Cardiol 2021. [In press].

10 Khan JM, Rogers T, Schenke WH, et al. Intentional Laceration of the Anterior Mitral Valve Leaflet to Prevent Left Ventricular Outflow Tract Obstruction During Transcatheter Mitral Valve Replacement: Pre-Clinical Findings. JACC Cardiovasc Interv 2016;9:1835-43.

Cite this article as: Edelman JJ, Squiers JJ, Mack MJ, Thourani VH. Best transcatheter approach for a failed mitral valve ring. Ann Cardiothorac Surg 2021;10(5):692-693. doi: 10.21037/acs2021-tviv-22 